\title{
Convention Decision Making Modeling
}

\author{
Anahita MalekMohammadi and Badaruddin Mohamed
}

\begin{abstract}
There are a few studies in which conceptual models explaining conference participation decision-making process are constructed and estimated. This study focus on convention decision making conceptual models and addresses those components which appear to be important and influential in the decision-making process. Understanding convention decision making factors helps association marketers to attract more delegates and thus gain more benefit from this important sector of tourism industry in future.
\end{abstract}

Index Terms-MICE, Decision-Making, Attendees, Convention Modeling

\section{INTRODUCTION}

A major segment of the international tourism market is business tourism. Business tourism considers as an economic significance to many countries worldwide (WTO, 2006). However, despite its economic importance, neither business tourism nor the meetings, incentives, conventions and exhibitions (MICE) industry has been particularly well researched or documented in recent years. Despite the importance of this significant sector of tourism industry, knowledge of the individual conference delegates and their needs and want is lacking. Most of previous researches on the MICE sector have focused mostly on the supply side. Research within this latter area offers an opportunity to advance knowledge in the area of conference tourism (Mair \& Thompson, 2009).

As explained by Chon (1991) convention business is fairly heterogeneous and one may differentiates between corporate meetings and association meetings. Business research also shows that there are different characteristics between these sectors. Oppermann and Chon (1997) believed that "Freedom of choice" on the side of the association meetings appears to be the main distinction because corporate meetings are usually a requirement for the employees. Most of participants in an association meeting have to fund their travel expenses themselves or obtain funding from a third party.

Mair \& Thompson (2009) acknowledge that, in some instances, delegates may attend as a result of a business decision by their company to send them. They argued that association conference delegates have a much higher degree of discretion in attendance than within the corporate conference sector, where attendance is often encouraged, if not dictated, by the employer.

According to Schiffman \& Kanuk (1997) recognizing why and how overseas convention attendees make their consumption decisions can assist the association/event organizers and the host location's tourism marketers in predicting and explaining how consumers are likely to react, permitting them to shape their marketing strategies accordingly, thus helping them to gain an even greater competitive advantage in the market place.

Only 3 convention attendee-related studies (Var et al., 1985; Oppermann \& Chon, 1997, Zhang, Leung and Qu, 2007) were found which focused on convention decision making modeling. The majority of studies focused on convention and meeting planner related studies (Bonn \& Boyd, 1992; Bonn, Brand, \& Ohlin, 1994; Oppermann, 1996; Go \& Zhang, 1997). This paper aims to review existing models of convention participation decision making to identify those components which appear to be influential in the decision-making process.

\section{Previous Models of Convention Decision Making}

Var, Cesario and Mauser (1985) developed the first convention tourism modeling. It was an econometric study concerned with the demand for conference tourism. They examined the determinants of conference attendance within a domestic context. They suggested that there are three variables which influence the level of conference attendance: accessibility, attractiveness and emissiveness.

Oppermann and Chon (1997) proposed two models in the areas of associations' location choice and participation decision-making variables of the attendees. Their first model addresses the interactions and interrelationships among associations, host locations, and attendees. While the second model clarifies the convention participation decision making process by potential attendees. In the second model the influencing variables are then categorized into personal/business factors, association/conference factors, location factors, and intervening opportunities. As a result, their paper suggested a structural model of association convention participation that integrates the three main actors which are host location, association meeting and potential attendees and discusses their relationships.

Zhang, Leung and Qu (2007) refined a new model of factors affecting convention participation decision-making using Oppermann and Chon (1997) model as their foundation framework and comprised four main dimensions, association/conference factors, personal/business factors, location factors, and total cost factors.

\section{A. Economic model of convention decision making}

Var, Cesario and Mauser (1985) introduced an approach for identifying the determinants of convention attendance in alternative cities. They explain the association meetings market as a system with three main players, the organizing association, the host location, and the potential attendees and 
suggest that a common purpose of both associations and host location is maximization of the number of delegates.

Witt, Sykes, \& Dartus (1995) explain that in Var, Cesario and Mauser (1985) econometric model, attendance considers by origin state at the annual conferences of the 'American Political Science Association' held over the period 1968-71 in four major cities in the USA. According to them there are three variables which influence the level of conference attendance: accessibility, attractiveness and emissiveness. 'Accessibility' was measured by distance (which was taken to be proportional to cost), 'attractiveness' by destination city variables, and 'emissiveness' by origin state variables. The attractiveness of a conference venue incorporates the influence of climate, leisure amenities, cultural activities, etc. The emissiveness of an origin refers to the tendency of members from that origin to attend annual conferences, and incorporates the 'combined effects of differentiating characteristics such as income, population, etc (P.20).

According to Var, Cesario and Mauser (1985) in Witt, Sykes, \& Dartus (1995) study, the log-linear specification of the model relates the number of conference trips from a given origin to a particular destination. There are three explanatory variables (accessibility, attractiveness and emissiveness) and the model was estimated by ordinary least square. Finally in the second stage of the study model, the authors explain differences in emissiveness - as measured by dummy variable coefficients - among origin states. Therefore, they concluded that association membership was the dominant determinant of emissiveness, as it accounted for $90 \%$ of the variations in emissiveness.

\section{B. Interrelationships among the main players in convention tourism}

Oppermann and Chon (1997) believe that besides the three main players introduced by Var and colleagues, there are several minor ones, for example all association meetings are held in conjunction with an exposition because exhibitors have a definite interest in conventions (ASAE 1992).

Organizing associations are the source of stimulation in order to attract as many participants as possible because conventions contribute a large share of their income (Shure 1994). Association organizers need to attract potential attendees by offering an attractive conference program, selecting an attractive convention site and by promoting the convention to the members. Oppermann and Chon 1997 explain that the association also has to reimburse the host location (i.e., conference center, conference hotel) for facility rental, entertainment, meal functions, and the like.

At the same time conventions also benefit the host location. They provide the host location both with a high-volume demand during the shoulder seasons and with a great exposure to many people (Oppermann and Chon 1997). According to Edelstein and Benini (1994) many delegates travel with their spouses to conventions' location, so their tourism activities benefit host location in many ways. Levels of income and revenue gain from convention sector have motivated host locations to plan strong competition strategies for more conventions (Oppermann and Chon 1997).

Attendees in Oppermann and Chon's Interrelationships Model has been split into 'participating members' and 'non-participating members' because usually the percentage of members that actually attend in an annual convention is very low while there is a considerable number of non-members who participate (ASAE 1992; Var, Cesario and Mauser 1985; Witt, Dartus and Sykes 1992 in Opprman and Chon 1997).

Attendees may also attend in groups and by their family or friends. Previous researches have shown that family members are important in the participation decision-making process (Oh, Roehl and Shock 1993). Attractiveness of some convention destinations may also cause a higher spouse turnout. It means that, attendees can enjoy the location for recreation and sightseeing. In the other hand, if the attendees have not been to the convention location it will give them a unique chance to visit the location (Opprman and Chon 1997).

\section{Attendees' participation decision-making process}

Oppermann and Chon (1997) developed a model explaining the conference participation decision-making process based on previous studies. The model represents a comprehensive analysis of all factors on the side of the potential attendee. It was a schematic presentation of the different factors involved in the conference participation decision-making process of an individual with a predisposition (need recognition) towards attending conferences.

According to them previous studies demonstrate that association convention decision making process is similar to the general tourism destination selection process. It means that behavior of a delegate who attends an association conference is significantly similar to the behavior of leisure tourists when deciding to go for a holiday (Oppermann and Chon 1997; Mair and Thompson 2009). There are certain steps which a potential tourist has to identify in the decision making process of leisure travel. Convention attendees will also go through this steps, at first they recognize a need to travel, after that information search starts that follows by evaluation of alternatives, product choice, outcome, and post-evaluation (Mair and Thompson 2009).

Oppermann and Chon (1997) explain that there are also several "push" and "pull" factors that are involved in convention decision making as well as barriers to attend and intervening opportunities. For example in form of conferences since potential participants usually have a wide range of association conventions and other conferences to choose from and do not and cannot attend all. Convention attendees may participate in a convention for completely different reasons. Little is known about the attendees and only a few recent studies have shed some light on the motivational aspects of convention attendees and non-attendees (Grant 1994; Oppermann 1995; Oppermann and Chon 1995; Price 1993).

Finally, they identified several variables influencing convention decision making process of attendees and grouped them into four categories: personal/business factors, association/conference factors, location factors, and intervening opportunities. 


\section{Refined model of factors affecting convention participation decision-making}

Zhang, Leung and Qu (2007) propose a refined model of factors affecting convention participation decision making using Oppermann and Chon's study (1997) as the foundation of their new model. The study differs from the previous model since they combined the opinions of other scholars and carried out a comprehensive analysis of all the factors that were identified from a review of the existing literature and their relative influence on convention attendance. They also examined attributes under each dimension carefully.

They believe that many factors are missing in Oppermann and Chon's (1997) study model. For example, a major consideration for delegates when deciding whether to attend a conference or convention is the cost, which includes the monetary cost and the time cost. So the new model contains two major modifications. Firstly, the original 'location factors' were split into two subcategories 'attractiveness' and "accessibility" of convention destination. Secondly, the original 'intervening opportunities' in Oppermann and Chon's model were replaced by 'total cost factor'. They discussed that as opportunity costs in using money and time are different, it is logical to further subdivide the total cost factors into 'total time cost' and 'total monetary cost' of the trip (Zhang, Leung and Qu 2007).

As a result their refined model of factors affecting convention participation decision-making comprises four main dimensions, association/conference factors, personal/business factors, location factors, and total cost factors.

\section{CONCLUSION}

This study aims to gain a better understanding of convention decision making components by reviewing previous convention decision making models. Consequently this study categorizes four influential factors which are cost, location, conference factors and personal/professional factors as the most common factors influencing convention decision making process from delegate's perspective. Future studies should test factors suggested in this study which is believed to be main influential factors in conference participation.

\section{REFERENCES}

[1] WTO. Tourism highlights 2006 edition. http://www.unwto.org/facts/menu.html. Accessed 3.12.06.2006.

[2] Mair, J. and Thompson, K., The UK association conference attendance decision-making process. Tourism Management, 2009, 30 (2009) 400-409.

[3] Chon, K. S. The Role of Destination Image in Tourism: A Review and Discussion. Tourist Review 45(2):2-4. 1991 Meetings Management and Hospitality/Tourism Industry, Cahiers du Tourisme, C 157. Aix-en-Provence: Centre des Hautes Etudes Touristiques.1989.

[4] Oppermann, M., and Chon, K. S., Convention participation decision-making process. Annals of Tourism Research, 1997, 24(1), 178-191.

[5] Schiffman, L. G., \& Kanuk, L. L. Consumer Behavior. 1997, (pp. 558-583) (6th ed). Englewood Cliffs, NJ: Prentice-Hall.

[6] Var, T., Cesario, F., \& Mauser, G. Convention tourism modeling. Tourism Management. 1985, 195-204.
[7] Bonn, M. A., \& Boyd, J. N. A multivariate analysis of corporate meeting planner perceptions of Caribbean destinations. Journal of Travel and Tourism Marketing, 1(3), 1-23. 1992.

[8] Zhang, H., Leung, V. A refined model of factors affecting convention participation decision-making. Tourism Management, 2007, 28, 1123-1127.

[9] Bonn, M. A., Brand, R. R., \& Ohlin, J. B. Site selection for professional meetings: a comparison of heavy-half vs. light-half association and corporation meeting planners. Journal of Travel and Tourism Marketing, 3(2), 59-84. 1994.

[10] Oppermann, M. Professional conference attendees' and non-attendees' participation decision factors. The Society of Travel and Tourism Educators Annual Conference, Denver, Colorado, 1995.

[11] Go, F., \& Zhang, W. Applying importance-performance analysis to Beijing as an international meeting destination. Journal of Tourism Research, spring, 42-49. 1997.

[12] Shure, P. PCMA's Third Annual Meetings Market Survey. Convene 9(2):32-64. 1994.

[13] Edelstein, L. G., and C. Benini. Meetings Market Report 1994. Meetings \& Convention 29(Aug.):60-82. Elwood, P. 1994.

[14] Association Executives. Association Management. The Impact of Association Meetings. Association Management 45(7):85-88. 1993.

[15] Witt, S. F., Sykes, A. M., \& Dartus, M. Forecasting international conference attending. Tourism Management, 1995, 16(8), 559-570.

[16] Oh, H. M., W. S. Roehl, ed., and P. Shock. Family Decision Making in Convention Participation. In Proceedings of the Convention/Expo Summit IV (pp. 35-51). Las Vegas: University of Nevada. 1993.

[17] Grant, Y. N. J. Factors that Contribute to the Selection Process of Meetings from the Perspective of the Attendee. Unpublished Masters thesis, Virginia Polytechnic and State University, Blacksburg.1994.

[18] Price, C., An empirical study of the value of professional association meetings from the perspective of attendees. Ph.D dissertation, Virginia Polytechnic and State University, Blacksburg, VA. 1993. 